\title{
First records of Heteroglenea nigromaculata (Thomson, 1865) (Cerambycidae, Lamiinae, Saperdini) from India
}

\author{
Gavas Ragesh ${ }^{1 *}$, Hemant V. Ghate ${ }^{2}$ \\ 1 Entomology-Nematology Division, Banana Research Station, Kerala Agricultural University, Kannara Post, Thrissur 680652, Kerala, India • \\ gavas.ragesh@kau.in (1) https://orcid.org/0000-0002-9014-0028 \\ 2 Post Graduate Research Centre, Department of Zoology, Modern College of Arts, Science and Commerce (Autonomous), Shivajinagar, Pune \\ 411005, Maharashtra, India • hemantghate@gmail.com @ https://orcid.org/0000-0003-4934-7542 \\ * Corresponding author
}

\begin{abstract}
We collected the longhorn beetle Heteroglenea nigromaculata (Thomson, 1865) (Cerambycidae, Lamiinae, Saperdini) for the first time in India. The presence of this species in Kerala, South India, considerably extends its distribution to the west. Though H. nigromaculata is known from adjacent countries such as China, Thailand, and Myanmar, it has not been documented from North or Northeast India. Adults were found in association with the Indian Screw Tree, Helicteres isora L. (Sterculiaceae). We include photographs of living H. nigromaculata and brief comments on morphology and colouration.
\end{abstract}

\section{Keywords}

Kerala, long-horned beetle, range extension, Western Ghats

Academic editor: Cheng-Bin Wang | Received 12 June 2021 | Accepted 19 August 2021 | Published 9 September 2021

Citation: Gavas R, Ghate HV (2021) First records of Heteroglenea nigromaculata (Thomson, 1865) (Cerambycidae, Lamiinae, Saperdini) from India. Check List 17 (5): 1237-1241. https://doi.org/10.15560/17.5.1237

\section{Introduction}

The genus Heteroglenea Gahan, 1897 (Cerambycidae, Lamiinae, Saperdini) was erected by Gahan (1897) with Glenea nigromaculata Thomson, 1865 (now Heteroglenea nigromaculata) as the type species and distinguished from the genus Glenea Newman, 1842 on the basis of the bifid anterior claws on all tarsi and the lack of distinct lateral carinae on the elytra (Gahan 1897; see also Lin and Tavakilian 2012). Many authors (e.g., Breuning 1956; Rondon and Breuning 1970) overlooked these characters, treated Heteroglenea as a synonym of Glenea, and continued to use Glenea for H. nigromaculata. Recently, Heteroglenea was reinstated by Lin et al. (2009), who redefined it with additional characters of the male genitalia, described three new species, commented on and provided synonyms of the six other included species, provided distribution data and key to all species.

Thomson's (1865) original Latin description of Glenea nigromaculata is just three and half lines and dealt only with colouration. While erecting the new genus Heteroglenea, Gahan (1897) synonymized his own species, Glenea? Amelia Gahan, 1889, with H. nigromaculata. As G. amelia was well described and Gahan gave all the important characters that are also seen in H. nigromaculata, we do not describe it in detail. Gahan (1894: 89) also gave a brief description of female $H$. nigromaculata from Burma (= Myanmar), noting that anterior claws are bifid in females as well and stating: “... the females are to be distinguished from the males by their somewhat larger 
size, shorter antennae, and by having the last abdominal segment broader, and impressed along the middle of its ventral surface by a feeble groove".

According to Lin et al. (2009), of the nine species presently classified as Heteroglenea, two occur in India, H. bastiensis (Breuning, 1956) and H. vicinalis Lin \& Yang, 2009, both from Darjeeling, West Bengal.

Kariyanna et al. (2017) included H. fissilis (Breuning, 1953) from India (without giving exact locality). Heteroglenea fissilis is from Sylhet, "India" (Lin et al. 2009), part of the former "British India", but now in Bangladesh. Thus, this species occurs very close to the Bangladesh-Indian border, but it is not known from India. With our addition here of $H$. nigromaculata, three species are now known in India.

Breuning (1956) redescribed Glenea (Glenea) nigromaculata in considerable morphological details, giving all known synonyms. Thus, we do not reiterate morphology and synonyms of $H$. nigromaculata in detail. We do provide photographs of living specimens to show the distinctive colouration of this species and a photograph of a mating pair to illustrate the size difference of the sexes. We also add a few comments on morphology and present a revised distribution map of this species.

\section{Methods}

During the surveys for pests of crops in Kerala, as part of a project under Indian Council of Agriculture Research - All India Coordinated Research Project on Fruits (ICAR-AICRP), one of us (GR) observed Heteroglenea nigromaculata on the campus of Kerala Agricultural University. The beetles were observed alive and photographs were taken with a Canon EOS 700D camera with a $100 \mathrm{~mm}$ macro lens or with OPPO mobile camera with the macro lens option used. One male and one female were later collected for morphological study. The distribution map of the species was prepared using QGIS v. 2.18.5 (https://qgis.org/downloads/). The data for the map were also excerpted from Lin et al. (2009), and the geographical coordinates of our new records were obtained using Google Earth Pro (https://www.google. com/intl/en_in/earth/versions/).

The two $H$. nigromaculata specimens were dried and pinned for detailed examination under a Leica S9i stereomicroscope. The male specimen is preserved in the collection of the Banana Research Station, Kerala Agricultural University, Kannara, Thrissur, and the female specimen is deposited in the collection of the Western Ghats Regional Centre, Zoological Survey of India, Kozikode, Kerala.

\section{Results}

Subfamily Lamiinae Latreille, 1825

Tribe Saperdini Mulsant, 1839

Genus Heteroglenea Gahan, 1897

\section{Heteroglenea nigromaculata (Thomson, 1865)}

Figure 1

Glenea amelia Gahan 1889: 224 (type locality: Thailand). For synonyms and distribution, see Lin et al. (2009)

New records. INDIA - Kerala state - Thrissur, Vellanikkara, Kerala Agricultural University main campus; $10^{\circ} 32^{\prime} 55^{\prime \prime} \mathrm{N}, 076^{\circ} 17^{\prime} 38^{\prime \prime} \mathrm{E}$; 11.V.2021; Gavas Ragesh leg.; 1 ô, KAUZC/GR/INV./E/2021/00011 • Thrissur, Vellanikkara, Kerala Agricultural University main campus; $10^{\circ} 32^{\prime} 55^{\prime \prime} \mathrm{N}, 076^{\circ} 17^{\prime} 38^{\prime \prime} \mathrm{E} ; 22 \mathrm{~m}$ alt.; 11.V.2021; Gavas Ragesh leg.; 1 , ZSI/WGRC/I.R./INV.17842.

Identification. The specimens were initially identified using the key and figure of this species by Rondon and Breuning (1970, as Glenea nigromaculata). We subsequently compared our specimens with figures of the types of $H$. nigromaculata and Glenea amelia provided by Lin et al. (2009). The bifid anterior claws were diagnostic of Heteroglenea. Our specimens match very well with the description of G. amelia by Gahan (1889) and detailed redescription of $G$. (G.) nigromaculata by Breuning (1956). The dorsal black maculae on the pronotum in $H$. nigromaculata are rounded, with their length less than two times their width (Fig. 1A), while in other species these maculae are elongate (Lin et al. 2009). In $H$. nigromaculata, the antennae are completely blackish brown. These two characters separate this species from all other congeners.

Small $(<10 \mathrm{~mm})$ : total length: male $7.5 \mathrm{~mm}$; female $8.3 \mathrm{~mm}$ and larger than male. Head slightly broader than prothorax. Prothorax as long as broad, slightly constricted at base, its width distinctly less than elytral width at humeri. Elytra nearly parallel-sided but abruptly narrowed in apical region, without distinct lateral carinae, coarsely punctured but punctures obscured by dense pubescence, truncate at apex but without spines. Prosternal process very narrow, parallel sided. Mesoventral process similar but slightly broader than prosternal process. Metaventrite slightly convex, with anterior projection between mesocoxae, with prominent median sulcus. Legs of moderate length, hind femora not reaching apex of abdomen. First and fifth abdominal ventrites longer than other ventrites which are all nearly of same length.

Tegument dark brown to black, covered with thick, yellow or grayish-yellow pubescence creating a bilaterally symmetrical pattern of yellow or gray pubescence and brown areas devoid of yellow pubescence. Long, dark brown or grayish-white setae sparsely cover body. In the images of the types, the pubescence is mostly grayish white or ashy gray than yellow, probably because the specimens are very old. In life, this pubescence is actually brilliant yellow in places and ashy gray elsewhere on the elytra and ventrites.

Head yellow in front, enclosing a small rounded black spot; frontal yellow pubescence extends back on occiput medially and appears bilobed due to small median black 

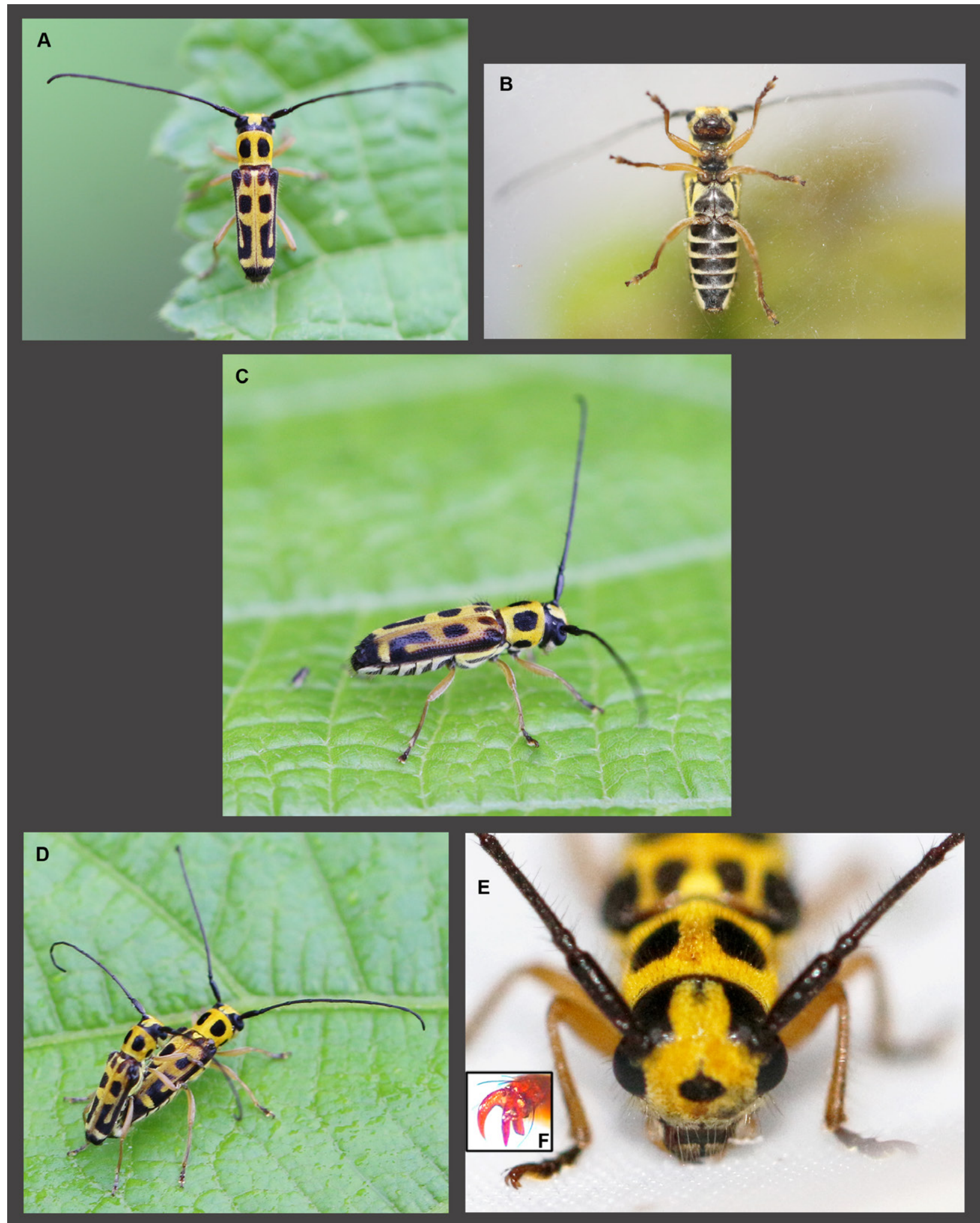

Figure 1. Heteroglenea nigromaculata (Thomson, 1865). A. Dorsal habitus. B. Ventral habitus. C. Dorsolateral habitus. D. Mating pair. E. Frontal view of head. F. Bifid claw.

area, leaving dark brown areas laterally behind eyes and dark extreme posterior margin. This dark posterior margin extends laterally and ventrally. Eyes black. Antennae entirely brownish black. Clypeus brownish; mandibles black; palps reddish brown.

The pronotum is yellow, with two dorsal and two lateral oval black areas. The dorsal spots are about 1.5 times longer than broad and larger than the lateral spots.

Elytra yellow with a pattern of black areas as follows: two black rounded spots at base, one on each side of grayish white scutellum. Humeral angles black, continuing as a black band along entire side for almost $80 \%$ of the length of the elytra, from where it turns inward towards the suture, then turns upward without meeting 
the suture. At the tip this band is broadly truncate. There is an oval black spot before the middle, in front of this truncated black band. Finally, there is an apical transverse black band (Fig. 1A, C).

Underside of the body mostly devoid of yellow pubescence, except for a triangular lateral patch on the metaventrite, which continues laterally and encloses a black elongate patch. A transverse apical band of ashy gray pubescence is present on each abdominal ventrite, and this band continues laterally to the base of each ventrite (Fig. 1B). This pattern of yellow/ashy gray and black is shown in Figure 1C. All coxae, femora, and tibia are reddish brown, and tarsi are darker.

Figure 1D shows a mating pair. Males and females have a noticeable size difference, with females being larger. In frontal view, the head has yellow pubescence enclosing a central, black, oval area (Fig. 1E). Figure 1F shows the diagnostic bifid anterior claw of the foreleg.

\section{Discussion}

In general, the morphological features of this species are similar to those of the other Heteroglenea reported from India. Due to the lack of laboratory facilities during the COVID-19 lockdown, we were unable to dissect the male genitalia, but all the other features seen in these specimens lead us to identify our specimens as $H$. nigromaculata. Our photographs should be helpful to naturalists and students of biodiversity in the accurate identification of this species of beetle. The mating pair and the other three individuals (not collected) were observed on plant Helicteres isora L., a medicinal plant of the family Sterculiaceae. We hope to study whether $H$. isora serves as host for egg laying and larval development of H. nigromaculata.

Although $H$. nigromaculata is known from China (Guangxi, Yunnan), Vietnam, Laos, Cambodia, Thailand, Myanmar, and the Philippines, it had not even been recorded from Indian Territory close to Myanmar. This may be due to the lack of extensive surveys. Our new records of $H$. nigromaculata from Kerala extend the geographic distribution of this species westward from Myanmar by about 2,500 km (Fig. 2). Heteroglenea nigromaculata appears to be the most widespread species in its genus, while the other eight species appear to have rather restricted distributions. The host plant of $H$. nigromaculata was reported to be Streblus asper Lour. (Moraceae) (Rondon and Breuning 1970). This plant, as well as three other Streblus species, are found in Meghalaya and Assam (Roy et al. 2013), and yet H. nigromaculata is unknown from those parts of India.

Some other species of Heteroglenea also occur in the neighbouring countries but are not yet recorded from similar habitats in India, and $H$. fissilis is an example of one such species. Our new records of H. nigromaculata underlines the fact that the distributions of most insects, as well as other invertebrates, from the Indian subcontinent are still very poorly known.

\section{Acknowledgements}

We are grateful to Dr. Mei-Ying Lin (Chinese Academy of Sciences, Beijing, China) for confirming our identification, for improving the first draft of this paper, and for helping us in many ways on this group of Lamiinae. Dr. Lin and Dr. Roberto Poggi (Museo Civico di Storia

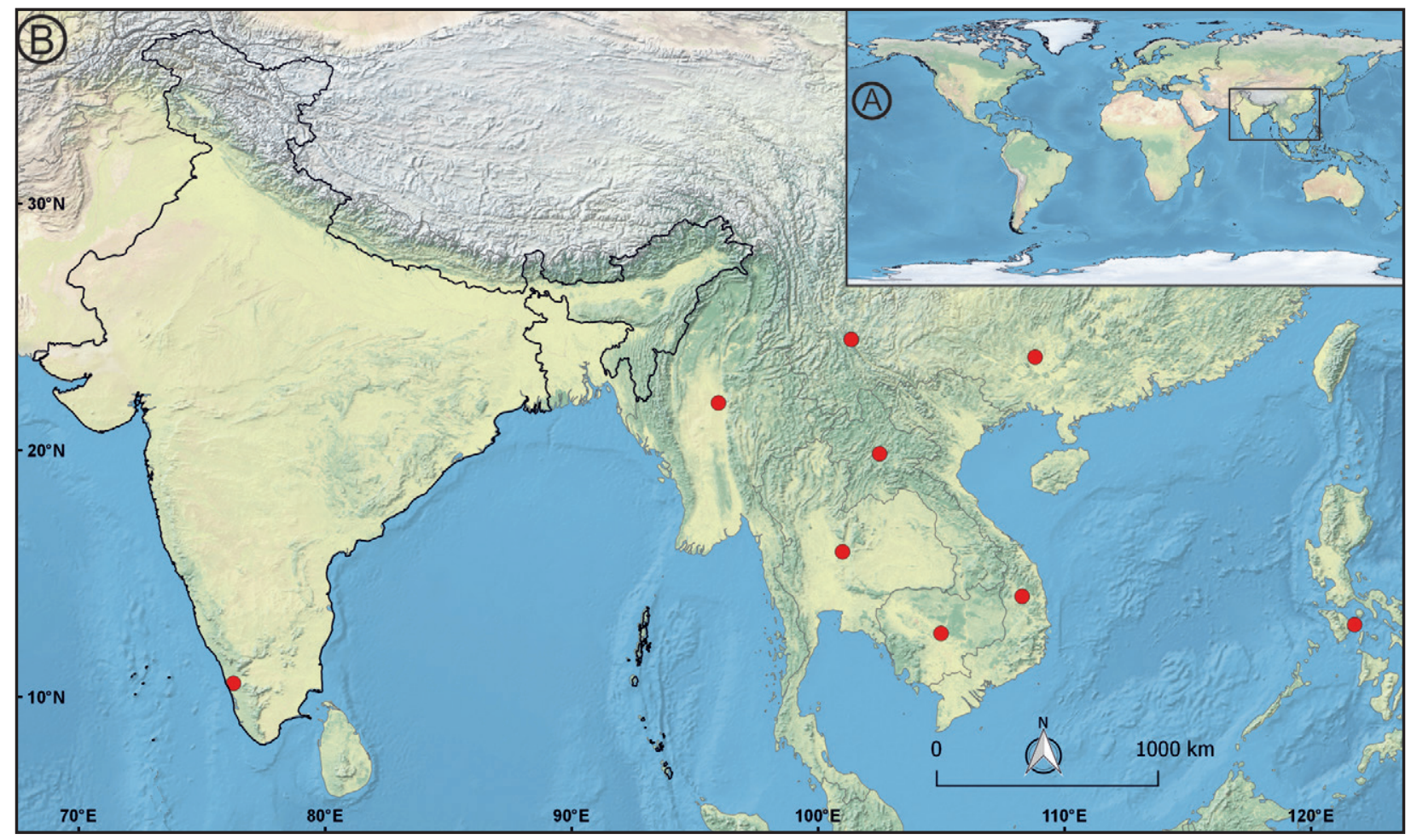

Figure 2. Map showing distribution of Heteroglenea nigromaculata (Thomson, 1865). 
Naturale, Genoa, Italy) helped us in determining the exact citation of one reference. We also thank the reviewers and the subject editor for improving and for processing this manuscript in short time. Gavas Ragesh sincerely thanks Dr. R. Chandra Babu (The Vice Chancellor, Kerala Agricultural University, Vellanikkara) for supporting and encouraging scientific research; he also thanks Dr. Prakash Patil (Project Coordinator, ICAR-AICRP on Fruits, ICAR-IIHR, Bengaluru) and Dr. P.B. Pushpalatha (Professor and Head, Banana Research Station, Thrissur) for their guidance. Facilities for microscopic work were kindly provided by Dr. T.V. Sajeev (Senior Principal Scientist [Forest Entomology], Kerala Forest Research Institute, Thrissur, Kerala). We thank Dr. Sayali Sheth for preparing the illustrations and Dr. Shruti Paripatydar (both from Annasaheb Kulkarni Department of Biodiversity, Abasaheb Garware College, Pune 4) for helping with formatting this manuscript. Hemant Ghate is grateful to Francesco Vitali (National Museum of Natural History, Luxembourg) for his continuous support over the years. We are indebted to the authorities of Modern College for facilities and encouragement provided to Hemant Ghate.

\section{Authors' Contributions}

Conceptualization: GR, HVG. Data curation: HVG. Formal analysis: HVG. Investigation: GR. Methodology: GR. Resources: HVG. Software: HVG. Visualization: GR, HVG. Writing - original draft: GR. Writing review and editing: HVG.

\section{References}

Breuning S (1956) Revision der Gattung Glenea Newman. Entomologischen Arbeiten aus dem Museum G. Frey 7: 1-199.

Gahan CJ (1889) Descriptions of new or little-known species of Glenea in the collection of the British Museum. Transactions of the Entomological Society, London 2: 213-225.

Gahan CJ (1894) Viaggio di Leonardo Fea in Birmania e regionivicine. LVI. A List of the longicorn Coleoptera collected by Signor Fea in Burma and the adjoining regions, with descriptions of the new genera and species. Annali del Museo Civico di Storia Naturale 34: 5-104.

Gahan CJ (1897) Notes on the longicorn genus Glenea, Newm., with descriptions of new species. The Annals and Magazine of Natural History (Series 6) 19: 473-493. https://doi.org/10.1080/0022 2939708680567

Kariyanna B, Mohan M, Gupta R, Vitali F (2017) The checklist of longhorn beetles (Coleoptera: Cerambycidae) from India. Zootaxa 4345 (1): 1-317. https://doi.org/10.11646/zootaxa.4345.1.1

Lin M-Y, Montreuil O, Tavakilian GL, Yang X (2009) Reinstatement of the genus Heteroglenea Gahan, with four new combinations, four new synonyms and three new species (Coleoptera: Cerambycidae: Lamiinae: Saperdini). Zootaxa 2137: 1-22. https://doi. org/10.11646/zootaxa.2137.1.1

Lin M-Y, Tavakilian GL (2012) A new genus Bifidunguiglenea gen. nov. is erected for the species Glenea gestroi Gahan (Cerambycidae: Lamiinae: Saperdini). PLoS ONE 7 (7): e40768. https://doi. org/10.1371/journal.pone.0040768

Rondon, JA, Breuning S (1970) Lamiines du Laos. Pacific Insects Monograph 24: 315-571.

Roy DK, Panday S, Sinha Bk, Sawmliana M (2013) Taxonomic note on Streblus Lour. (Moraceae) in Northeast India. NeBio 4: 50-54.

Thomson J (1865) Diagnoses d'espèces nouvelles qui seront décrites dans l'appendix du systema cerambycidarum. Mémoires de la Société Royale des Sciences de Liège 19: 541-578. 